\title{
Striped Coral-Root
}

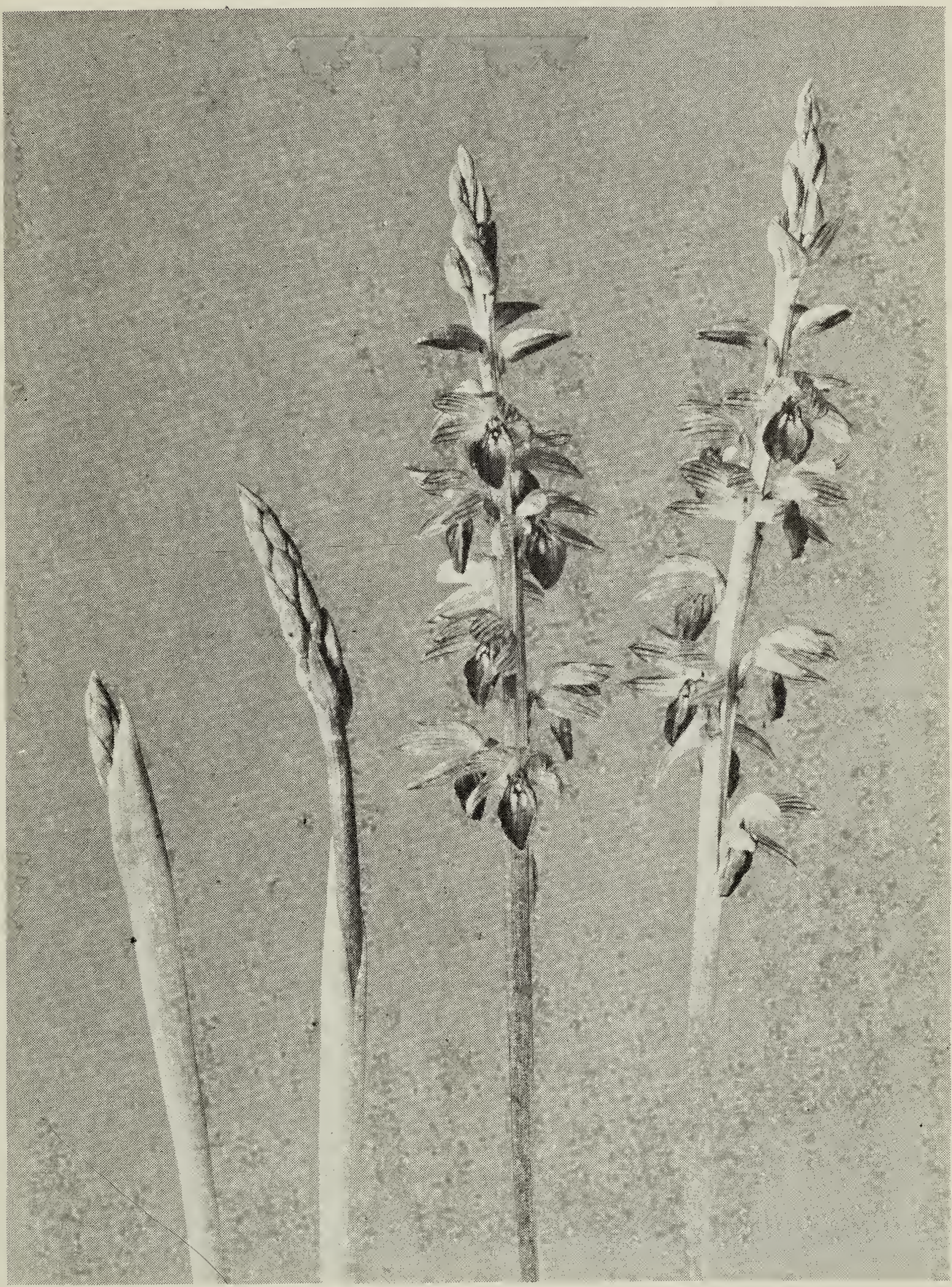

Photo by the late Dr. W. C. McCalla

Corallorhiza striata Lindl.

The Coral-roots are saprophytic orchids which do not have green leaves. They can not manufacture their food but obtain it from organic matter in the soil. They have thick coral-like rhizomes. The Striped Coral-root, found in rich woods of all three prairie provinces, is usually purplish with darker purple stripes on the sepals and petals. 